Review

\title{
Overview of Human Walking Induced Energy Harvesting Technologies and Its Possibility for Walking Robotics
}

\author{
Hu Shi ${ }^{1,2, *}$, Zhaoying Liu ${ }^{1}$ and Xuesong Mei ${ }^{1}$ \\ 1 School of Mechanical Engineering, Xi'an Jiaotong University, Xi'an 710049, Shaanxi, China; \\ lingxia7du@stu.xjtu.edu.cn (Z.L.); xsmei@xjtu.edu.cn (X.M.) \\ 2 State Key Laboratory of Fluid Power and Mechatronic System, Zhejiang University, Hangzhou 310027, \\ Zhejiang, China \\ * Correspondence: tigershi@xjtu.edu.cn; Tel.: +86-29-8266-3870
}

Received: 14 November 2019; Accepted: 19 December 2019; Published: 23 December 2019

\begin{abstract}
This study is mainly to provide an overview of human walking induced energy harvest. Focusing on the proportion of all energy sources provided by daily activity, the available human walking induced energy is divided with respect to the generation principle. The extensive research on harvesting energy results from body vibration, inertial element, and foot press to convert into electricity is overviewed. Over the past decades, various smart materials have been employed to achieve energy conversion. Generators based on electromagnetic induction or the triboelectric effect were developed and integrated. Small captured power and low overall efficiency are criticized. The concept of human walking energy harvest is extended into the wearable walking robotics using other mediums, such as fluid, to transmit power instead of electricity. By comparison, it is indicated that less energy conversion links are involved in energy regeneration of such applications and expected to guarantee less loss and higher efficiency. Meanwhile, in order to overcome the shortage of relatively low power output, comments are made that the harvester should be capable of adaptation under the condition that the mechanical energy of lower limb and feet is subject to change in different gait phases so as to maximize the collected energy.
\end{abstract}

Keywords: biomedical mechanics; energy harvesting; energy storage; exoskeleton; gait; hydraulic system; accumulator

\section{Introduction}

Energy is a basic need in human life, and people are consuming more and more energy for doing their activities with the emergence of home appliances and wearable electronics [1,2]. The human body contains enormous amounts of energy produced by metabolism and is a promising energy source to harvest. Potential in power generation due to typical types of movements performed daily by a commonplace human body with a medium build is illustrated in Figure 1 [3,4]. Generally, the major energy provided by the human body results from limb movement, heat, and biochemical potentials. Among these three types of energy sources, body motion produces the most. It is estimated that energy generated by these sources is as considerable as capable of powering computers and other electronics indispensable in modern daily life [5]. 


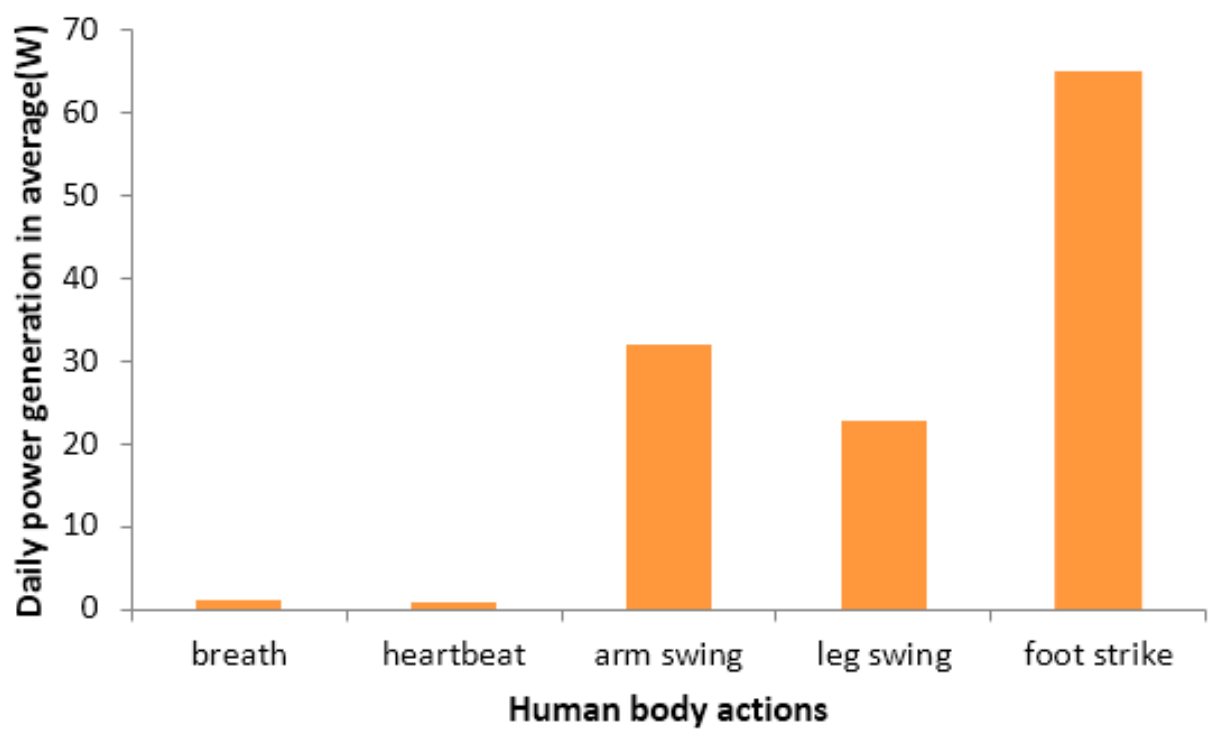

Figure 1. Energy generated by typical types of human movements.

Harvesting energy available in vivo, such as the biochemical energy in bio-fluid, is relatively difficult, and the output power signal is weak [6]. On the other hand, a thermoelectric generator can be used to get electric energy from human body heat. The recent achievements on various applications of thermoelectric devices have been made promisingly. As shown in Figure 2, an energy harvesting test with a thin layer of polydimethylsiloxane (PDMS) spread on a wrist conducted at a room temperature of $17.2^{\circ} \mathrm{C}$ proved that power of more than $10 \mu \mathrm{W} / \mathrm{cm}^{2}$ could be generated at a normal walking speed, and it can spread across various body locations additionally [7]. Although energy produced either by harvesting on clothes or taping the device directly to the skin is only several micro Watts, it proves to be a reliable power supply for low-power wearable electronics like wireless electrocardiography $[8,9]$. However, it has to cover more area of the human body in order to obtain more output power, which may make people feel uncomfortable.

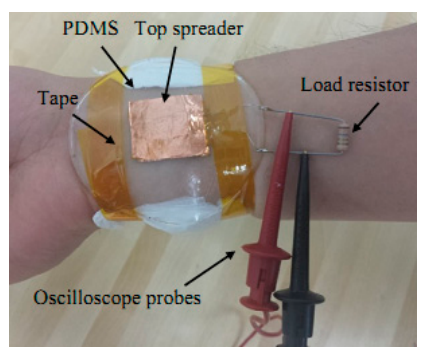

(a) Device on the wrist for arm swing test

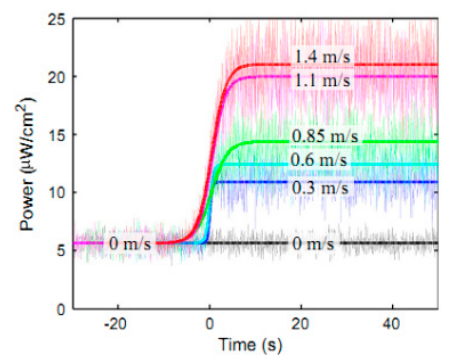

(b) Power generated at different walking speeds

Figure 2. Thermoelectric generator attached onto the upper arm [7].

In contrast, interest in harvesting energy from human walking has grown tremendously. Human walking induced energy is much easier to harvest and convert into electricity in relatively greater quantity because it contains the kinetic and potential energy of the body. Primarily, human walking induced energy takes three forms, generated from foot strike, body inertia, and vibration. Since foot-ground contact during walking produces considerable biomechanical energy, efforts to capture energy from foot strike by planting the harvester beneath the shoes have been taken extensively recently [10-15]. While walking, the center of mass of the human body as well as limbs moves continuously and yields inertia energy. Special mechanisms can be designed to achieve movement transformation from translation to rotation and drive an electric generator to generate power [16-18]. Basically, human walking is composed of a series of periodic motions, and mechanical vibration 
exists inevitably. A majority of efforts have explored harvesting mechanical energy from vibrating objects (cars, buildings, etc.) along with human-induced vibrating motions [19-21]. Furthermore, a triboelectric generator based on the triboelectric effect has also attracted researchers' interests to fabricate the flexible structures from nanotechnology and harvest energy from a walking human body [22,23].

Overall, the previous research work seems to fall short of expectations in the following aspects.

(i) Research motivations have been confined to the supply power for portable, wearable, or even implanted electronic devices. In consideration of the long-term vision and more extensive application, the wearable frames that assist humans to move and take steps have the potential for energy regeneration, such as a gait orthotic system and exoskeleton [24,25].

(ii) Harvested energy tends to suffer from insufficient output power. The energy produced by foot strike is in large quantity. So, how to find a more effective energy conversion and management way is a challenging subject, regarding the interdisciplinary knowledge of mechanical design, materials, circuit, power transmission, and control, etc.

(iii) Storage and arrangement of captured energy is as important as energy conversion to achieve effective recovery. Various batteries are easy to access for commercial use, irrespective of limited capacity and energy efficiency, so no special effort has been made on this topic [26]. Electricity generation is a very convenient way to transfer energy, but it is difficult to store in quantities to meet the diversity of customer demand [27].

The rest of this paper is arranged as follows. Section 2 provides a detailed review of the research progress of the existing human body motion energy conversion methods. Section 3 is about the research progress of human walking induced energy storage. Challenges from capture, storage, and utilization and their possible solutions are elaborated in Section 4. Prospects are discussed, and recommendations are presented in Section 5 with a concern for a high efficiency energy recycling applied in the wearable robot fields, followed by conclusions in Section 6.

\section{Human Walking Induced Energy Conversion}

Essentially, human walking induced energy that can be used potentially exits in the form of mechanical energy. For energy recovery, it has to convert into energy in a certain form that can be regulated freely. Electric energy is the desirable form when it comes to the flexibility of distribution and utilization, so the researchers generally take electricity as the energy form after conversion. There are four commonly adopted ways to generate electricity: using smart materials, electrostatic capacitance converter, the triboelectric effect, and electromagnetic induction. The feasibility corresponding to the different types of energy sources is estimated, as shown in Table 1.

Table 1. Optional ways to capture available energy sources.

\begin{tabular}{cccc}
\hline Energy Sources & Foot Stepping & Inertia Energy & Vibrations \\
\hline Smart materials & $\sqrt{ }$ & $\sqrt{ }$ & $\sqrt{ }$ \\
Electromagnetic induction & $\sqrt{ }$ & $\sqrt{ }$ & $\sqrt{ }$ \\
Triboelectric effect & $\sqrt{ }$ & & $\sqrt{ }$ \\
Electrostatic capacitance & & & $\sqrt{ }$ \\
\hline
\end{tabular}

\subsection{Smart Materials Based Harvester}

Smart materials can change physical properties significantly in a controlled fashion by external stimuli, such as stress, electric, or magnetic fields. Benefiting from the superior properties, a variety of miniaturized energy harvesters made of such materials has attracted widespread attention from researchers continuously. 


\subsubsection{Piezoelectric Materials}

Due to its advantages of simple architecture, piezoelectric materials are easy to fabricate into energy harvesters of different configurations [28]. It is quite suitable for harvesting energy from the compression motion performed by foot strike. So, embedding such harvesters into insole is the most common way to harvest human walking induced energy [29]. In practice, the effective deformation of the piezoelectric material is relatively small when the human foot strikes directly, and the amount of electricity generated is very limited. In order to improve the output power of such insole harvesters, amplification mechanisms were proposed to increase the effective strain in the piezoelectric material, as shown in Figure 3 [16]. With novel amplification mechanisms, the effective strain can be greatly improved, and the output electric power is much more than the harvester of traditional constructions [30]. It is reported that the magnetic rotary generator can produce approximately two orders of magnitude more power than either of the piezoelectric systems [14-16]. However, in contrast with traditional generators, the harvester with smart material is much easier to integrate smoothly into the design of common footwear without much interference to the shoe or gait [31].

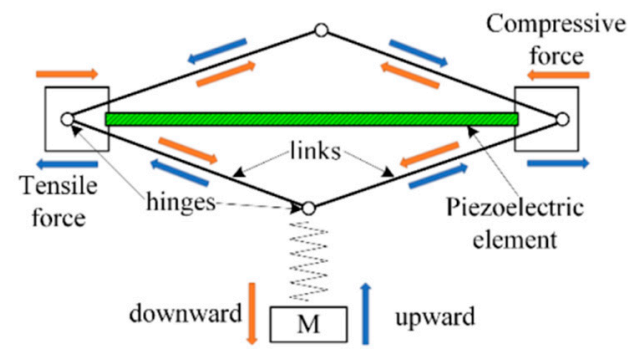

Figure 3. Truss-based compressive-mode piezoelectric energy harvester [29].

Vibration energy harvest is another manner of addressing the same issues in microsystems applications [32]. Different from the aforementioned research focused on the foot locomotion, a collection of human-walking-induced vibration energy is realized at the other parts of the human body, such as the back and leg. Unlike ambient vibrations or acoustic waves from the surrounding mechanical systems, human walking produces random excitation to the harvester and brings nonlinearities into the energy harvesting system [33]. Previous research has provided many solutions for developing simple and efficient vibrational energy harvesting devices using piezoelectric materials [34-36]. Such smart structures and integrated systems may facilitate a walking energy harvesting transducer with consideration of the exclusive excitations of human beings compared with mechanical vibrations.

Due to the intense acceleration and deceleration of the foot, inertial mechanisms are more suitable for absorbing energy. From this aspect, the piezoelectric backpack harvesting the walking human body inertia energy is proposed by replacing the traditional strap of the backpack with that made of the piezoelectric polymer, and it can obtain $45.6 \mathrm{~mW}$ of power [37]. However, the randomly generated low-frequency excitation of human limbs must be transformed into a higher transducer frequency to realize energy harvesting [38].

\subsubsection{Other Smart Materials}

The dielectric elastomer has high strain energy, but it requires a high pre-charge voltage (typically up to several thousand volts) to produce a current when the material is compressed to deform $[39,40]$. It is attractive in many applications, including artificial muscles, micro-valves, intelligent endoscopes, etc. [41,42]. When the small generator, shown in Figure 4, is placed into a military boot heel to harvest human walking energy from foot strikes, it can generate up to $1 \mathrm{~W}$ of electricity by taking one step a second [43-45]. In addition, magnetostrictive material and magnetic shape memory alloy are also most frequently concerned as they perform energy conversion efficiently [46,47]. Many efforts are devoted to vibration energy harvesting with those materials, and mechanical kinetic energy has been converted 
into electrical energy successfully [48-50]. It is significant to develop human walking induced vibration energy generation technology in practice and may become true in the future after the issues of external excitation differences between mechanical systems and the human body are completely settled.

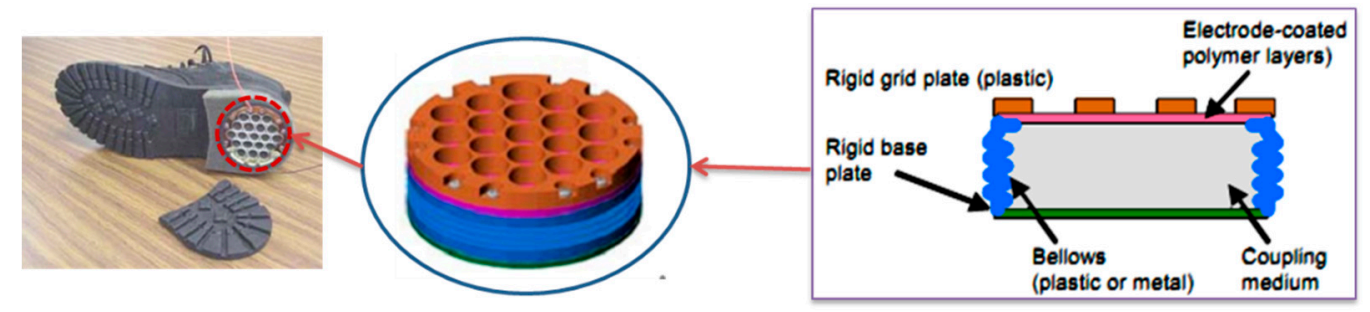

Figure 4. Dielectric elastomer powered boot generators [43].

\subsection{Electromagnetic Induction Generator}

Electromagnetic induction is supposed to be the most primary way to generate electricity. Studies suggested that, in most cases, the maximum energy harvested by means of an electric generator is higher than that generated with smart materials [51-54]. Furthermore, an energy harvester with smart materials has to be embedded into the shoes while an electromagnetic induction motor has no such limitations. The basic idea of a human-powered generator is using the human body motion to make the permanent magnet and inductive coil perform the relative movement to output electricity. Therefore, the relative velocity of the permanent magnet and inductive coil induced by the human walking motion is the key factor to improve the output power of the generator.

\subsubsection{Traditional Generator}

The foot striking action leads to the relative movement between the feet and ground. It makes the possibility of using a compact generator to harvest energy. For example, an insole generator developed by MIT uses a mechanical system coupled with a flywheel, and it can generate up to $1.2 \mathrm{~W}$ of power during a standard walk [55]. However, this generator's working stroke is up to $3 \mathrm{~cm}$, which may bring inconvenience to the wearer. The research group also hosts twin motor-generators along with step-up gears embedded directly into a sneaker's sole (without springs or flywheels for energy storage) and produces $60 \mathrm{~mW}$ of electricity under the same condition. After all, a generator is so bulky that it usually takes much room. In contradiction to such demands, there is only limited space available for embedding at the foot and sole interface.

Human walking induced vibration energy can be collected nearly on every part of the human body, so the electric generator design has more flexibility. Studies conducted over the last few years mostly placed a harvester in a backpack carried by shoulders to recover energy $[16,21,56]$. Such backpack was designed based on the assumption that a person walks like an inverted pendulum, in which the hip traces out an arc over an extended leg with a vertical excursion of $5 \mathrm{~cm}$ or so. With the prototype shown in Figure 5, power generation can reach a maximum of $7.4 \mathrm{~W}$ at the speed of $6.4 \mathrm{~km} / \mathrm{h}$ when the participant is carrying 20-38 kg loads [57]. Additionally, the human walking-induced vertical movement of the load in the gravitational field is also a promising energy source. However, compared with mechanical vibration, human-induced oscillations are challenging for energy harvesting because of low-frequency, aperiodic, and time-varying characteristics [58,59]. 


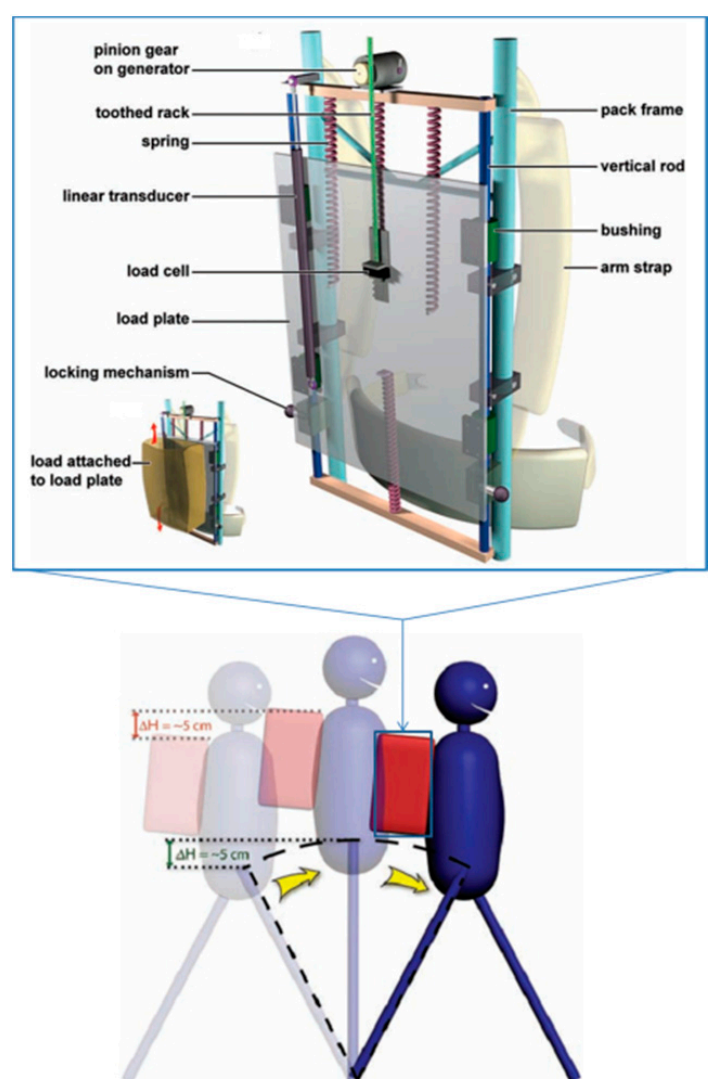

Figure 5. Suspended-load backpack undergoing vertical excursion [57].

Since the human body is subjected to the severe acceleration and deceleration during walking, the inertia mechanism is more suitable for energy absorption and accumulation. The exemplary inertial generator harvesting human body energy can date back to the 18th century, which is a self-winding watch integrated with a small inertial energy harvester $[60,61]$. The mechanical transmission system operates together with the electromagnetic transducer. This invention is still serving for a variety of commercial products [62].

Investigations proved that the lower limb produces much kinetic energy by the swing motion of human walking. Hence, a generator can be mounted on the knee brace as demonstrated in Figure 6, the working principle of which is the same as the energy storage brake on the hybrid electric vehicle [63-66]. It is not only capable of outputting more power than the insole generator but is lighter than the backpack generator. It can be used by tourists or soldiers to get through an emergency where power supply is temporarily unavailable. Furthermore, a magnetically plucked wearable knee-joint energy harvester was designed by researchers to scavenge energy from knee-joint motions during human walking and power an energy-aware wireless sensor node for data sensing [67]. Another interesting work related to inertial energy harvest is presented by Shan et al. in Ref. [68], where a free rotating inertia block and a fixed coil are adopted to design a power generation device to capture the kinetic energy of human walking. This device is more encouraging than the self-winding watch that utilizes the motion of the user's arm to accelerate a small internal mass [69]. 


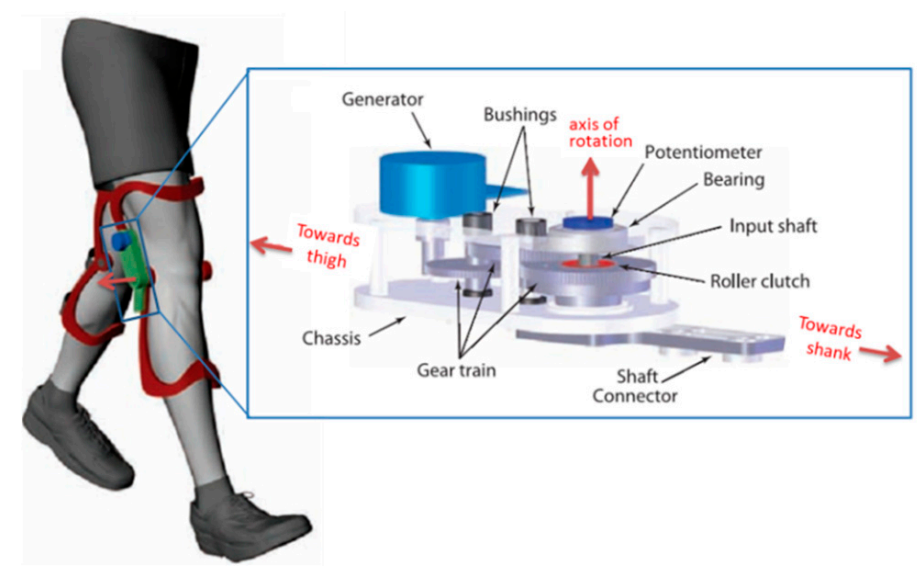

Figure 6. Energy harvester mounted on orthopedic knee brace [66].

Although the rotational generator can operate efficiently, it is difficult to achieve continuous output because a complete revolution is hardly made with the inconsistency of the walking movement, and mostly, the rotating mass cannot be too large to interfere with the wearer. Therefore, more and more attention has been paid to the linear inertia generator that collects energy in the daily action of the human body [70]. The inertia force generator can be taken as a kind of spring mass system, including inertia mass, spring, and damper. The electromagnetic inertia generator is expected to provide enough power for implantable medical devices, such as artificial heart or joints [71].

\subsubsection{Generator with Liquid Metal}

The working principle of the generator based on liquid metal is similar to that of an electromagnetic generator. The liquid metal flow cuts the magnetic lines and converts mechanical energy into electrical energy. The feasibility of its application in energy recovery has been studied previously [72,73]. Some research works have also been conducted to consider harvesting human walking induced energy with the matter [74]. Although the power generation by the liquid metal generator is only in the micro watt scale, its attempt has opened up a new field for human power generation. Moreover, the reverse electrowetting technique based on liquid metal to capture the mechanical energy of the human body can increase output power density to as high as $103 \mathrm{~W} / \mathrm{m}^{2}[75,76]$.

\subsection{Triboelectric Generator}

The triboelectric effect is a very common physical phenomenon that appears in daily life. Based on the principle, the concept of the triboelectric nanogenerator (TENG) was firstly proposed by Wang a few years ago [77]. Since then, great attempts about the applications of the triboelectric nanogenerator have been demonstrated by his research group continuously with original and innovative contributions to the synthesis, discovery, characterization, and explanation of fundamental physical properties of this kind of device [78-82]. His invention and achievements provided an alternative for harvesting mechanical energy from environmental and biological systems.

When carrying a triboelectric nanogenerator built inside the insole to harvest walking-induced energy, electricity can be generated as soon as the human walks. Based on the cycled contact-separation between a polydimethylsil-oxane (PDMS) film and a polyethylene terephthalate (PET) film, a simple fabrication and cost-effective triboelectric nanogenerator with outstanding performance was developed. During the test conducted in $10 \mathrm{~s}$, the instantaneous maximum power value was nearly $1.4 \mathrm{~mW}$ by changing the resistor from $10^{3}$ to $10^{8} \Omega$ [78]. The basic structure of such devices used to produce triboelectric energy and output the current is a thin film only nanoscale in thickness, so the generator can be made soft and transparent [79]. Furthermore, the approach to create the simple-to-fabricate, high-performance, wearable, and all-fiber triboelectric nanogenerator based insole with a composition of electrospun piezoelectric polyvinylidene fluoride (PVDF) nanofibers sandwiched between a pair 
of conducting fabric electrodes that effectively harvests energy from vibration caused by foot strikes during human walking was proposed, as shown in Figure 7 [80]. In previous research, the PVDF material together with nylon has proven to be very suitable for fabricating the fully self-powered and portable detection devices [81].

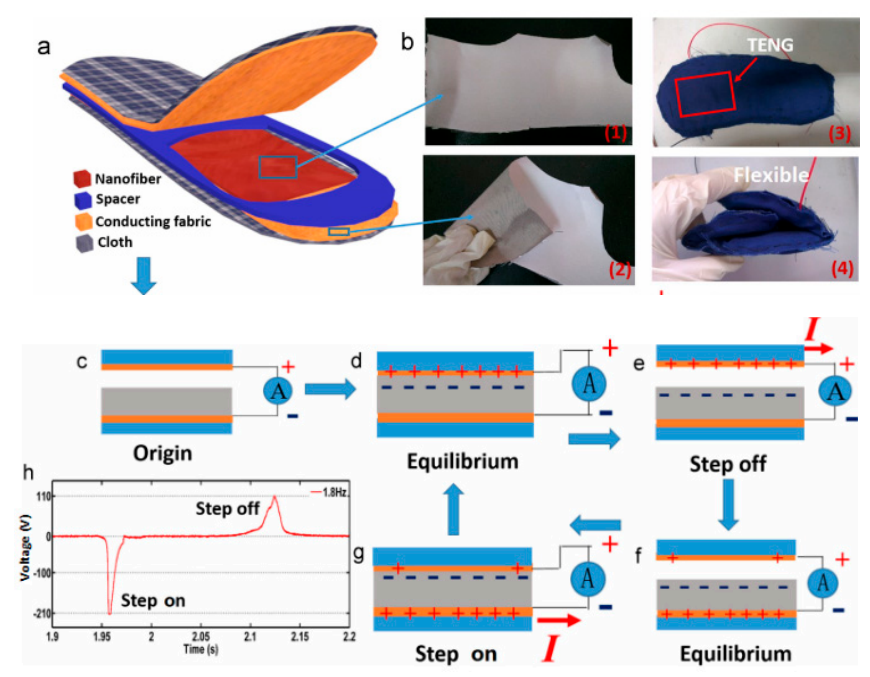

Figure 7. Schematic of a triboelectric nanogenerator based insole [80]. (a) TENG embedded into insole; (b) PVDF nanofibers; (c-g) working mechanism of the TENG when the device is in the states of origin, equilibrium, step off, equilibrium, step on; (h) voltage-time curve.

Since triboelectric charge is very common on the human body from a variety of ambient sources, it can exist at nearly any location of the human body. For instance, triboelectric nanogenerators can also be fabricated based on a human skin patch to harvest biomechanical energy. It makes use of the periodic contact/separation between an area of human skin and polydimethylsiloxane (PDMS) film with a surface of specially designed novel structures and can achieve relatively high energy conversion efficiency $[83,84]$. As an effective energy source, this device shows great potential in human-machine interfacing and micro/nano-electromechanical systems.

\subsection{Electrostatic Energy Conversion}

Harvesting vibration energy from human body can also be achieved by an electrostatic generator [85]. In essence, such devices are mechanically variable capacitors of which plates are separated by the movement of the source [86]. Accordingly, the electrostatic capacitive energy converter can be employed to realize vibration-to-electricity energy conversion, but the efficiency is not as high as expected $[87,88]$. Moreover, it needs to be precharged to initiate the conversion process. An electrostatic generator of small size is particularly suitable for microelectromechanical systems and acts as the portable vibrational energy harvester of the human walking motion [89,90]. To obtain the best results, vibration caused by human walking has to be at a frequency as close to the resonance frequency of the transducer as possible. In practice, human walking produces the mechanical excitations at lower frequencies compared with the vibration from mechanical systems. This is part of the reason for the fact that the electrostatic energy conversion is actually rarely studied.

\section{Human Walking Induced Energy Storage}

Converting human walking motion into energy available for regulation and utilization is the first step for developing self-powered devices. Since the mechanical energy generated during human walking suffers from dramatic change, the directly captured energy usually cannot deliver in a steady state. In order to maintain a continuous energy supply, it is very necessary to conduct energy regulation or output rectification. 


\subsection{Considerations for Energy Storage}

Since energy storage is crucial for walking induced energy harvest and reuse, energy loss in the process and convenience to release energy for utilization should be concerned. Meanwhile, energy storage may involve energy form change, reducing the efficiency of both storage and discharge links. Obviously, energy conversion between different forms inevitably leads to loss and even other unfavorable factors, such as heating, degrading the system performance. On the other hand, the energy conversion and storage system have to be attached to the human body and follow the walking movements, so the procedures should be simple and easy. It is desired to choose an appropriate energy form so that the energy harvest can be done conveniently.

\subsection{Frequently Adopted Energy Storage Methods}

Many kinds of energy storage systems have been developed to meet the requirements of various applications, simply divided into chemical and physical energy storage. An electric energy storage system mainly comprises batteries, control, and power conditioning systems [91,92]. The batteries are made of stacked cells where-in chemical energy is converted into electrical energy and vice versa by electrochemical reactions. Many types of batteries can be found, taking their specific advantages in either energy efficiency or self-discharge rates $[93,94]$. There are also other emerging electric energy storage techniques that are currently not yet used as extensively as batteries on a commercial basis [95]. Actually, electrical energy storage is a difficult subject because it always suffers from energy conversion along with energy loss. As for batteries, power density and safety are also unfavorable restraints for the integrated system. So, efforts have been made on energy conversion mechanisms, but little is reported on storage to construct a rechargeable system with human walking induced energy [96].

\section{Challenges and Possible Solutions}

\subsection{Limitations of Current Energy Harvest Techniques}

\subsubsection{Energy Conversion}

Low energy conversion efficiency is a pronounced problem. For instance, the electric power collected through piezoelectric material is still relatively trifle in quantity, although a great number of researchers have been dedicated to the technique. The current research is focused more on improving the energy conversion efficiency by changing the physical and geometric parameters of harvesters. It is reported that the energy conversion efficiency of the material itself is limited by many interior factors. Another limitation is the quantity of power obtained from the harvester. Human walking can produce considerable energy in daily life, but the harvested energy reported in the references mostly stays at the microwatts level $[97,98]$. Throughout the previous studies, the electromagnetic induction effect based harvesters get the most energy, but the results are not optimistic, referring to those listed in Table 2 for comparisons. In fact, although the energy generation resulting from walking-induced footfall reaches as much as dozens of watts, the acting force direction of the foot is changing with time. Variation of the foot posture in different gait phases brings about difficulty in capturing the maximum energy from the human walking motion through the whole cycle [99].

Table 2. Output power of several typical human motion driven generators.

\begin{tabular}{cc}
\hline References & Generated Electricity $(\mathbf{W})$ \\
\hline Paradiso et al. [55] & 0.25 \\
Rome et al. [16] & 7.4 \\
Donelan et al. [65] & 5 \\
Saha et al. [56] & $0.3-2.5 \times 10^{-3}$ \\
Wei et al., 2009 [71] & $0-0.55$ \\
\hline
\end{tabular}




\subsubsection{Energy Storage}

In the current research, energy harvested from human walking motion has to be stored in the form of electricity. Unfortunately, not enough effort has been taken on the issue within the research field of human walking induced energy harvest. Battery energy storage is not a new topic but still challenging in many applications. Attentions related to electric energy storage are mostly paid to the large plants, such as wind farms, because of frequent supply and demand fluctuations [100,101]. By contrast, energy generated by human walking motion is much less in quantity, so the energy storage efficiency should be given special attention. Apparently, the relatively low efficiency is the weakness of the battery because either charging for storage or discharging to power electronics is always accompanied by energy loss. As shown in Figure 8, energy is converted from electrical energy to chemical energy during charging and inversely during discharging. The charge and discharge efficiency of a battery usually falls into the range of $80 \%$ to $90 \%$. Generally, a lithium ion battery has higher efficiency and power density, but it is significantly less compared with that of fossil fuels, of which the value is equal to about 1\% [102-104]. Furthermore, safety and environmental protection are also major problems in the case that the battery is embedded into the energy harvesting system and attached to the human body all the time [105]. Until now, such problems encountered in other applications where the battery is taken as a power source have not been solved effectively.

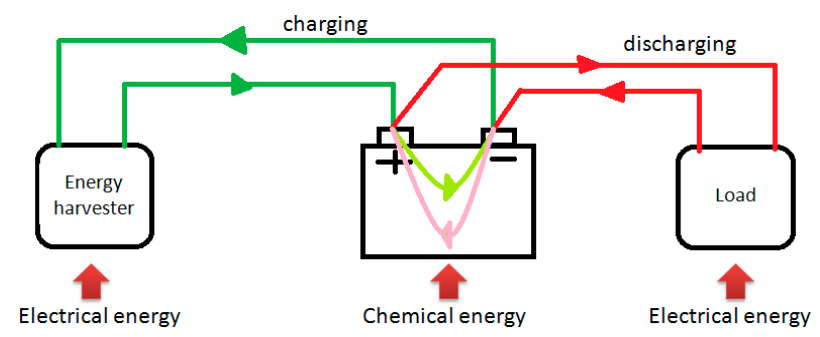

Figure 8. Energy conversion between charging and discharging of the battery.

\subsubsection{Use of Regenerative Energy}

The current energy harvesting system is used to charge portable electronic devices. As illustrated in Figure 9, these rechargeable electronics, everything from laptop computers to cell phones to flashlights, are tightly associated with people's daily life. Considering the human-assisted exoskeleton as a kind of wearable mechatronic system for augmentation or rehabilitation, saving energy and extending battery life or duration of any other power source by energy regeneration are extremely important. In fact, the wearable harvester attached onto a human body can function at any movable location theoretically because it follows the human body motion [106]. So various energy sources can be found, and more biomechanical energy can be captured from footfalls to vibration, or even inertia energy to aid limb motion [107]. Furthermore, since the generator produces alternating current, it must be converted into DC power. So, the harvesting circuit, including a rectifier and DC-DC converter, should be configured, especially along with an algorithm for the DC-DC converter to implement the optimal power transfer strategy and maximize the power extracted from generators and stored by the battery $[108,109]$. Finally, it should be noticed that rectification of the alternating polarity of the voltage and current to power portable devices or charge batteries is usually achieved with a reduction of about $5 \%$ in electrical power [57]. 


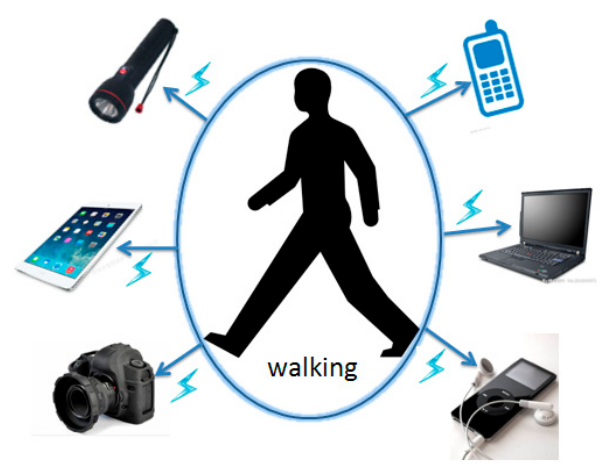

Figure 9. Typical utilizations of harvested human walking induced energy.

\subsection{Potential Solutions}

Basically, human walking induced kinematic energy belongs to mechanical energy. The currently proposed harvesters need to convert mechanical energy into electrical energy and then serve as power sources [110]. Conversion leads to energy loss and reduction of efficiency inevitably. In order to avoid the loss of this link, it is absolutely preferable to consider the application object that uses up mechanical energy directly instead of converting in advance. As a result, wearable mechanical devices are suitable candidates in response to this specific requirement. For example, the harvester can be functioning like a suspended-load ergonomic backpack to reduce the extra energy cost of carrying loads [111]. Similarly, aiming at reducing the energy cost of human walking and making it easier, Steven et al. developed an unpowered exoskeleton, shown in Figure 10, with spring storing and returning energy during each step; energy is restored by the lightweight and simple mechanical frame [112].

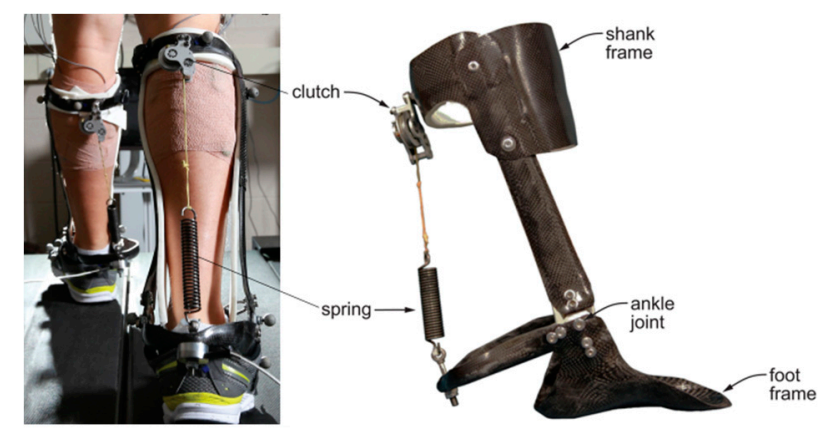

Figure 10. Device for reducing human metabolic energy during walking [112].

In a purely mechanical system without electricity, the spring acts as an energy storage component and recycles the energy mechanically and then does work to other wearable devices like a prosthetic foot mechanically [113]. Further, fluid power drive systems have been designed as an assist system with feasibility for use in hybrid neuroprostheses or ankle-foot orthosis [114,115]. Obviously, this design also contributes to the improvement of energy efficiency.

\subsubsection{Improving Energy Efficiency}

Seeking an alternative energy form for harvest and reuse is a promising solution to get a breakthrough in energy harvesting, especially for the wearable mechatronic systems like exoskeletons. A powered exoskeleton is basically a wearable walking robot developed for rehabilitation or physical augmentation of the wearer. It is usually powered by a system of electric motors, pneumatics, hydraulics, or a combination of technologies. Since fluid power is easier to transfer and control, its application of walking energy harvesting could be an ideal practice to perform energy saving on such robotic systems [116]. The pneumatic system has functioned in such a biomechanical system of small power as self-powered ankle-foot orthosis by generating power with an air pump embedded into 
the sole $[117,118]$. As shown in Figure 11, with a simple pneumatic circuit energy delivered by air compression was captured when the foot pressure was acting on the sole during walking.

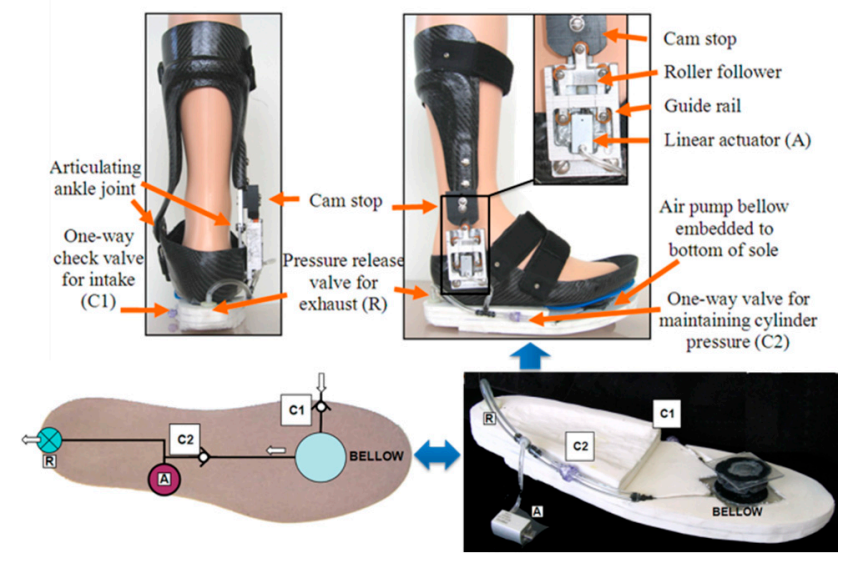

Figure 11. Ankle-foot orthotic device with pneumatic energy harvesting [116].

For a powered exoskeleton, hydraulic drive system may be superior to that of electric motors in terms of energy efficiency partly because amplifier losses usually should not be underestimated in power consumption [119]. From the aspect of energy flow, transformations in the electric system take place at least four times over the whole process. As shown in Figure 12, electric energy has to be converted into chemical energy for storage, making the process complex to some extent. In contrast, that is simple for a hydraulic drive system because change only takes place between mechanical and hydraulic energy. Moreover, hydraulic energy can be stored easily and do work directly. Obviously, more links mean more energy loss, and less energy loss definitely improves the energy efficiency of the entire process. So, it is expected to achieve the high efficiency energy harvesting objective by converting human walking mechanical energy into hydraulic energy.

\section{$>$ Energy conversion}

With the development of fabrication technology of hydraulic components and systems in the micro scale, robots driven by micro hydraulic actuators have emerged in the past few years, featured by compact structure and higher power to weight ratio $[120,121]$. Such micro hydraulic systems with excellent drive performance provide a promising solution for the wearable robotic equipment like an exoskeleton. For instance, a hydraulic energy harvester can be designed and embedded into the insole with reference to the other harvesters reviewed above. As shown in Figure 13, the harvester works based on the principle of a volumetric pump and supplies high pressure fluid when the foot is applying downward forces. The walking induced energy is regenerated by high pressure fluid, and then the energy conversion is achieved. As for component fabrication, additive manufacturing has been employed to make the integrated hydraulic actuation system for a legged robot and has proven its significant performance in constructing compact and lightweight drive units [122,123].

$>$ Energy storage

Energy storage is complicated in an electrical system, and it takes a long time to charge the battery. The electric signal transmitted during the energy conversion process has to suffer from rectification before electric energy storage [124]. The hydraulic power system, by contrast, is characterized by the combination of energy conversion and storage with an accumulator to realize easily. Furthermore, the consistent use of regenerative energy is particularly significant to the efficiency improvement. Hence, compact and powerful energy storage devices are required at any time. Comparisons of electrical, mechanical, and hydraulic energy storage devices illustrated in Figure 14 show that the classical hydraulic accumulator has very good superiority [125]. The 
energy efficiency of hydraulic drives has increased dramatically over the past decades, taking advantage of its easily implemented energy regeneration [126,127]. Similar to the bulky frame of the battery, the fluid energy storage device is usually not a lightweight component. It is critical, especially for mobile application, and should be improved by reducing the weight. With the emerging new material and the advanced manufacturing technology, such components with a mass reduction of more than $50 \%$ compared to the metallic structure have been reported [128]. This achievement is very exciting for the current fluid power system and makes it possible to expand the application scope of the fluid energy storage device.

$>$ Energy utilization

Since hydraulic energy can be converted into mechanical energy and perform work directly, the energy regulation and distribution has more flexibility when applied in the energy harvesting system. Consequently, the exoskeleton robot system for human power assistance driven by hydraulic actuators still owns a large share in the field applications, sharing the market together with electric drives, especially dedicated for the lower limb assistance or prosthesis, which usually consumes more power [129-131]. Taking advantage of relatively simple energy conversion and storage procedures, a hydraulic drive system with energy regeneration design could be more attractive in practice and rightly cover the shortage results from energy efficiency in most cases [132]. It is indicated that a great quantity of energy can even be regenerated and feedback to the hydraulic drive system of a wearable lower extremity, focusing on the walking induced energy merely by foot strike [133]. As illustrated in Figure 15, it definitely benefits from the shorter energy transfer chain than the electric system. With a properly designed accumulator, it can not only store hydraulic energy in high density but also absorb shocks brought about by frequent foot strike and lift movements.

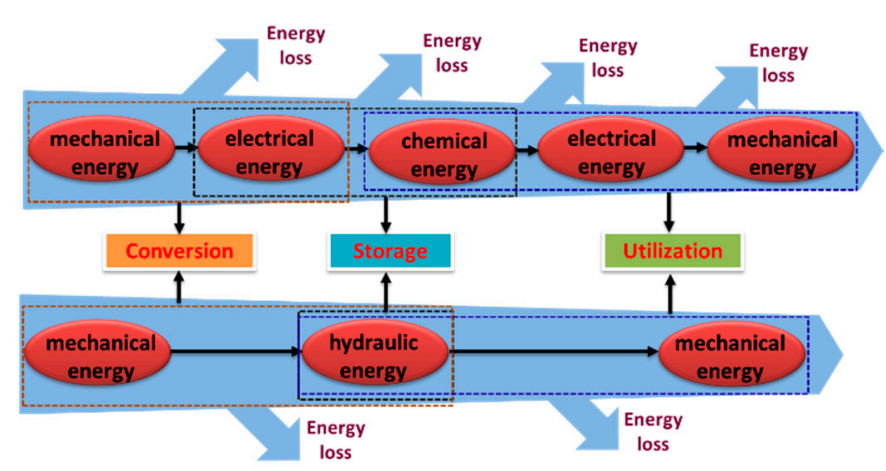

Figure 12. Schematic of energy flow in different energy harvesting systems.

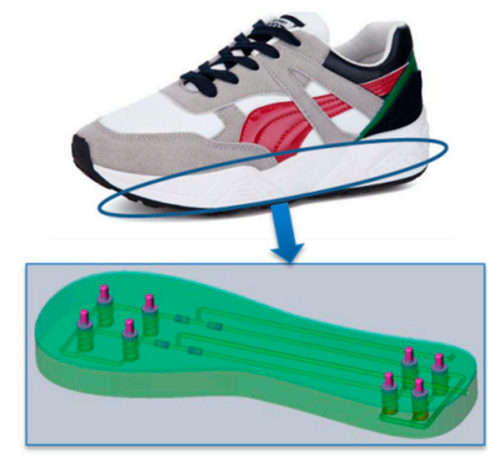

(a)

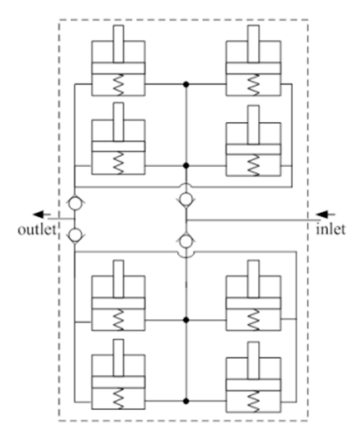

(b)

Figure 13. Micro insole embedded hydraulic energy harvester; (a) insole regeneration mechanism; (b) hydraulic circuit. 


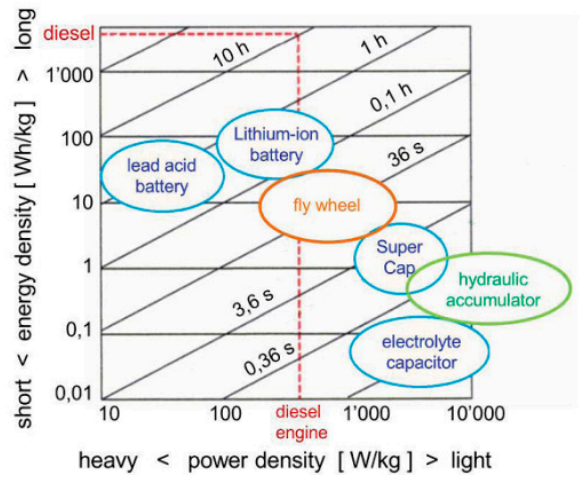

Figure 14. Performance comparisons of various energy storage devices [125].

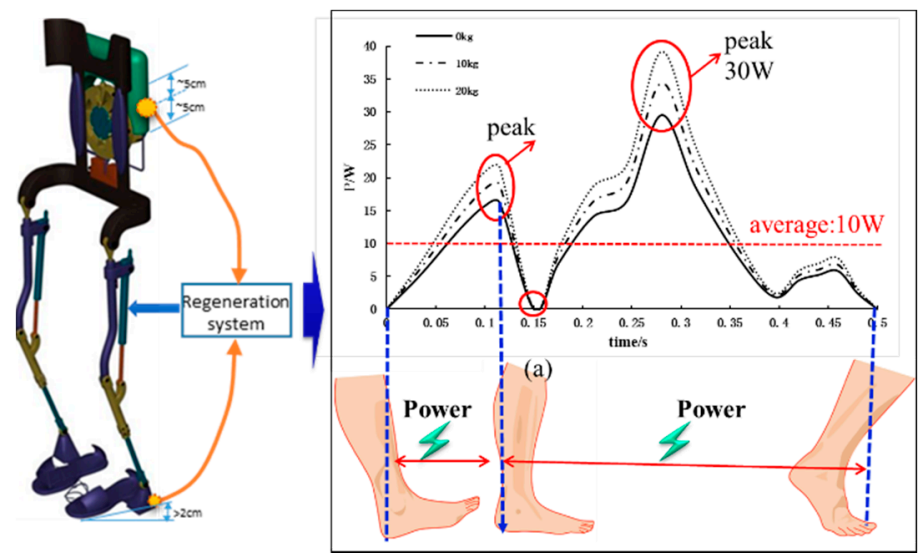

Figure 15. Walking energy harvesting with hydraulic power conversion [133].

\subsubsection{Maximizing the Captured Power}

As mentioned above, energy harvesting can be implemented from many movable parts of the human body. Among all potential energy sources, foot strike induces most energy in quantity. So, it should better attach the harvester onto feet or into shoes in order to maximize the captured energy, as the previous research does usually. However, the force acting on the ground by foot strike is subject to variation during a gait cycle. Interactions provide the forces necessary for propulsion and equilibrium during human locomotion [134]. Biologically, the human walking gait is divided into stance phase and swing phase, with an approximate duration ratio of six to four $[135,136]$. For a single foot, energy generation caused by pressing on the ground happens in the stance phase. In this phase, foot interacts with the ground, and the generated force can be decomposed into the components in three directions. Data can be collected with the participation of subjects. As shown in Figure 16, three componenets $F x$, $F y$, and $F z$ were normalized to body weight in order to allow comparison, and the length of each period is expressed as percentages of the stance phase [137,138]. Obviously, both direction and magnitude of the ground reacting force resulting from human walking change with the gait cycle all the way. So, the maximum energy induced changes too, and recovery of maximum energy should be carried out along the direction of the acting force as possible. However, the existing research on human walking induced energy harvest falls short of the in-depth analysis of the human walking gait, and the motion characteristics of the lower limbs are often considered in an approximate manner when designing harvesters. The inaccurate model definitely limits the efficiency of energy recovery. Therefore, human walking induced lower limb dynamics are very important to energy harvesting. The harvester should be designed specially to adapt to the variation of energy caused by foot strike. Investigation into the distribution of power carried by foot with respect to time and space is very necessary so that the harvester can be designed specially and efficiently. 


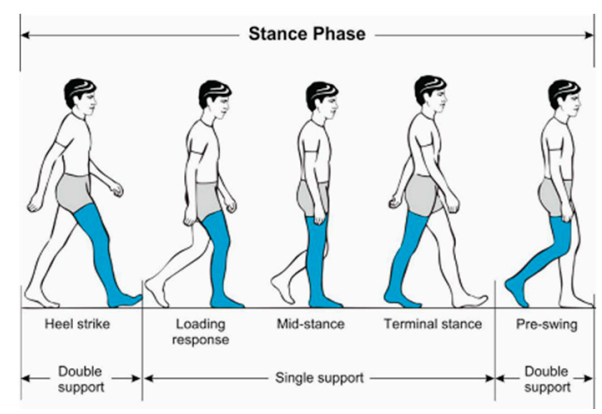

(a) gait cycle and phases

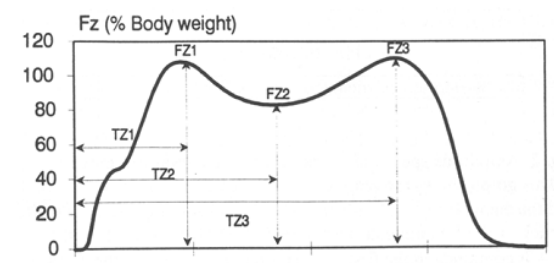

(b) ground reaction force in $\mathrm{z}$ direction

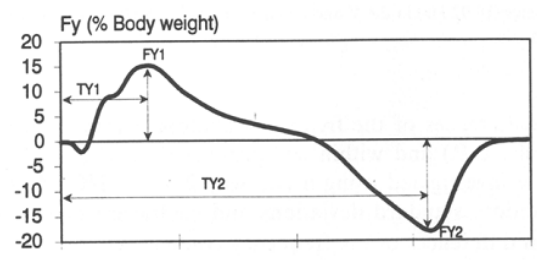

(c) ground reaction force in y direction

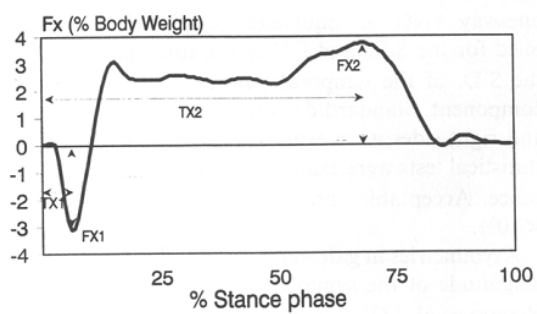

(d) ground reaction force in $\mathrm{x}$ direction

Figure 16. Stance phase of gait and ground reaction forces in the time domain [137].

\section{Prospects}

Walking is one of the most common human activities of daily living and a complex behavior consuming enormous metabolic energy. It is estimated that an average-sized person stores as much energy in fat as a one-ton battery, indicating the high power density of the human body energy system [139]. The artificial energy supply is far away from this capacity. Currently, many ways of harvesting energy from human walking and its related motion have been investigated. Their pros and cons are listed in Table 3. Obviously, different ways are potential for different applications. As shown previously, one of the biggest problems in human walking induced energy harvest is low power output, gleaning between milliwatts and microwatts [140]. So, exploring the effective means to increase the energy available for use is still of significance in the future. For instance, trying new energy forms to perform energy recovery, and it no longer seems to be confined to electricity of which energy storage is not so easy to realize. A mechanical or fluid system may be attempted to harvest the human walking induced energy, in light of a less complicated procedure. Higher efficiency and less energy loss are expected in the circumstances. Moreover, the energy harvester should be compact and lightweight to achieve greater ratios of power to volume and to weight, which is commonly pursued by such applications that have to attach something to the human body but avoid annoying the user. 
In addition, the energy harvesting devices are placed very close to the human body, so they should be designed and integrated based on ergonomics so as to wear comfortably and conveniently [141]. The less influence on the human body, the better people feel. It would be ideal for the wearer to enjoy walking in the same way as walking freely without any accessories.

Table 3. Comparison of different ways of harvesting energy from human walking.

\begin{tabular}{|c|c|c|c|}
\hline Different Ways & $\begin{array}{c}\text { Power } \\
\text { Obtained }\end{array}$ & Advantages & Shortages \\
\hline Smart materials & small & Compact/lightweight & Limited to light LEDs \\
\hline Electromagnetic induction & medium & $\begin{array}{l}\text { Fixed at many locations } \\
\text { around body }\end{array}$ & $\begin{array}{l}\text { Complex/bulky, difficult for } \\
\text { storage }\end{array}$ \\
\hline Triboelectric effect & small & integrated/lightweight & Affected by covered area \\
\hline Electrostatic capacitance & small & compact/lightweight & $\begin{array}{l}\text { Depend on the mechanical } \\
\text { vibration frequency }\end{array}$ \\
\hline Spring & large & $\begin{array}{l}\text { No conversion of } \\
\text { mechanical energy and } \\
\text { direct storage }\end{array}$ & $\begin{array}{l}\text { Release at the location of storage, } \\
\text { poor flexibility for use }\end{array}$ \\
\hline $\begin{array}{l}\text { Fluid power } \\
\text { (pneumatics, hydraulics) }\end{array}$ & large & $\begin{array}{l}\text { Integration of harvest } \\
\text { and utilization, easy for } \\
\text { storage and transmission }\end{array}$ & $\begin{array}{l}\text { Need pipelines, limited to } \\
\text { walking machines or robotics } \\
\text { driven by fluid power }\end{array}$ \\
\hline
\end{tabular}

\section{Conclusions}

This paper primarily provides an overview of various human walking induced energy harvesting techniques, from the aspects of conversion, storage, and utilization. Based on the analysis of the previously conducted and ongoing research activities, recommendations were made for harvesting the energy from human walking and utilizing wearable robotics. The conclusions can be drawn as follows.

(1) Human walking induced energy can be produced in great quantity and it is possible to be captured. The energy caused by the walking motion may either result from body vibration or exist as inertial energy of moving limbs, or even do work by interactions between foot and ground. It is of great significance to exploit the human walking action that keeps generating mechanical energy continually.

(2) Various parasitic harvesters have been made with smart materials and different types of generators based on electromagnetic induction, triboelectric effect, or electrostatic effect. However, from the aspect of energy saving of drive and mechatronic systems aiming at doing work rather than merely lighting LEDs, conversion from kinetic into electric energy involves a complicated process to some extent and vice versa. Further, electric signals have to be rectified, together with relatively complex procedures of energy storage and utilization, the overall energy efficiency of the harvesting system gets low and it cannot reach the expectations.

(3) Energy harvesting on the walking and wearable robotics seems more promising in efficiency. Converting mechanical energy into fluid power could be more direct with less energy loss. Under the circumstance, energy conversion, storage, and utilization can be realized easily within an integrated system. It is appropriate for the artificial exoskeleton to achieve power augmentation or assisting rehabilitation of lower limb because these robotic devices perform walking motions simultaneously. Such applications are expected to increase the duration of robots with batteries of certain capacity as the power supply or reduce the installed power and volume of the drive unit effectively.

Author Contributions: H.S., Z.L. and X.M. wrote the paper. All authors have read and agreed to the published version of the manuscript.

Funding: This work was supported by the National Natural Science Foundation of China (No. 51675400), the open fund of the state key laboratory of fluid power and mechatronic system (No. GZKF-201712). 
Conflicts of Interest: The authors declare no conflict of interest.

\section{References}

1. Mateu, L.; Moll, F. Review of energy harvesting techniques and applications for microelectronics. Microtechnol. New Millenn. 2005, 359-373.

2. Starner, T. Human-powered wearable computing. IBM Syst. J. 1996, 35, 618-629. [CrossRef]

3. Niu, P.; Chapman, P.; Riemer, R. Evaluation of motions and actuation methods for biomechanical energy harvesting. In Proceedings of the 2004 IEEE 35th Annual Power Electronics Specialists Conference, Aachen, Germany, 20-25 June 2004; pp. 2100-2106.

4. Guo, Y.; Zhang, Q.; Li, Y.; Wang, H. Progress of the research on wearable triboelectric nanogenerator. Mater. China 2016, 35, 91-100.

5. Hansen, B.J.; Liu, Y.; Yang, R. Hybrid nanogenerator for concurrently harvesting biomechanical and biochemical energy. ACS Nano 2010, 4, 3647-3652. [CrossRef] [PubMed]

6. Leonov, V. Thermoelectric energy harvesting of human body heat for wearable sensors. IEEE Sens. J. 2013, 13, 2284-2291. [CrossRef]

7. Hyland, M.; Hunter, H.; Liu, J.; Veety, E. Wearable thermoelectric generators for human body heat harvesting. Appl. Energy 2016, 182, 518-524. [CrossRef]

8. Kim, M.; Lee, S.; Kim, C.; Kim, Y. Wearable thermoelectric generator for harvesting human body heat energy. Smart Mater. Struct. 2014, 23, 105002. [CrossRef]

9. Weber, J.; Potje-Kamloth, K.; Haase, F. Coin-size coiled-up polymer foil thermoelectric power generator for wearable electronics. Sens. Actuators A Phys. 2006, 132, 325-330. [CrossRef]

10. Xie, L.; Du, R. Design and analysis of a mechanical device to harvest energy from human footstep motion. Chin. J. Mech. Eng. 2011, 24, 738-743. [CrossRef]

11. Fu, H.; Xu, R.; Seto, K. Energy Harvesting from Human Motion Using Footstep-Induced Airflow. In Journal of Physics: Conference Series; IOP Publishing: Bristol, UK, 2015; p. 012060.

12. Choi, Y.M.; Lee, M.G.; Jeon, Y. Wearable biomechanical energy harvesting technologies. Energies 2017, 10, 1483. [CrossRef]

13. Anton, S.R.; Sodano, H.A. A review of power harvesting using piezoelectric materials 2003-2006. Smart Mater. Struct. 2007, 16, R1-R21. [CrossRef]

14. Jung, W.S.; Lee, M.; Kang, M. Powerful curved piezoelectric generator for wearable applications. Nano Energy 2015, 13, 174-181. [CrossRef]

15. Vineesh, K.; Amarnath, K.T.; Lavanya, M.; Priya, R.A. Review on foot step power generation by piezoelectric transducer. Int. J. Appl. Eng. Res. 2015, 10, 3814-3816.

16. Li, Z.; Y., Z.; Naguib, H.E.; Zu, J. Design and studies on a low-frequency truss-based compressive-mode piezoelectric energy harvester. IEEE Trans. Mech. 2018, 23, 2849-2858. [CrossRef]

17. Huang, H.; Merrett, G.V.; Metcalf, C.D.; White, N.M. A feasibility study on body-worn inertial energy harvesting during walking and running. Energy Harvest. 2011, 2, 272973.

18. Kuo, A.D. Harvesting energy by improving the economy human walking. Science 2005, 309, $1686-1687$. [CrossRef]

19. Yang, W.; Chen, J.; Zhu, G.; Yang, J. Harvesting energy from the natural vibration of human walking. ACS Nano 2013, 7, 11317-11324. [CrossRef]

20. Galhardi, M.A.; Guilherme, T.H.; Junior, V.L. A review of power harvesting on mechanical vibration using piezoelectric materials and applications. In Proceedings of the 7th Brazilian Conference on Dynamics, Control and Applications, São Paulo, Brazil, 7-9 May 2008.

21. Rao, Y.; McEachern, K.M.; Arnold, D.P. A compact human-powered energy harvesting system. Energy Harvest. Syst. 2013, 1, 89-100. [CrossRef]

22. Bai, P.; Zhu, G.; Lin, Z.; Jing, Q. Integrated multilayered triboelectric nanogenerator for harvesting biomechanical energy from human motions. ACS Nano 2013, 7, 3713-3719. [CrossRef]

23. Yi, F.; Lin, L.; Niu, S.; Yang, P.K. Stretchable-rubber-based triboelectric nanogenerator and its application as self-powered body motion sensors. Adv. Funct. Mater. 2015, 25, 3688-3696. [CrossRef]

24. Shorter, K.A.; Xia, J.; Hsiao-Wecksler, E.T. Technologies for powered ankle-foot orthotic systems: Possibilities and challenges. IEEE/ASME Trans. Mech. 2013, 18, 337-347. [CrossRef] 
25. Zoss, A.B.; Kazerooni, H.; Chu, A. Biomechanical design of the Berkeley lower extremity exoskeleton (BLEEX). IEEE/ASME Trans. Mech. 2006, 11, 128-138. [CrossRef]

26. Zhu, W.H.; Zhu, Y.; Davis, Z. Energy efficiency and capacity retention of Ni-MH batteries for storage applications. Appl. Energy 2013, 106, 307-313. [CrossRef]

27. Luo, X.; Wang, J.; Dooner, M.; Clarke, J. Overview of current development in electrical energy storage technologies and the application potential in power system operation. Appl. Energy 2015, 37, 511-536. [CrossRef]

28. Liu, H.; Zhong, J.; Lee, C.; Lee, S.W.; Lin, L. A comprehensive review on piezoelectric energy harvesting technology: Materials, mechanisms, and applications. Appl. Phys. Rev. 2018, 5, 041306. [CrossRef]

29. Zhao, J.; You, Z. A shoe-embedded piezoelectric energy harvester for wearable sensors. Sensors 2014, 14, 12497-12510. [CrossRef]

30. Xie, L.; Cai, M. Increased piezoelectric energy harvesting from human footstep motion by using an amplification mechanism. Appl. Phys. Lett. 2014, 105, 143901. [CrossRef]

31. Kymissis, J.; Kendall, C.; Paradiso, J.; Gershenfeld, N. Parasitic power harvesting in shoes. In Proceedings of the Digest of Papers. Second International Symposium on Wearable Computers, Pittsburgh, PA, USA, 19-20 Octorber 1998; pp. 132-139.

32. Beeby, S.P.; Tudor, M.J.; White, N.M. Energy harvesting vibration sources for microsystems applications. Meas. Sci. Tech. 2016, 17, R175-R195. [CrossRef]

33. Ahmed, R.; Mir, F.; Banerjee, S. A review on energy harvesting approaches for renewable energies from ambient vibrations and acoustic waves using piezoelectricity. Smart Mat. Struct. 2017, 26, 085031. [CrossRef]

34. Bian, Y.; Yang, C. A review of current research for energy harvesting based on vibration of piezoelectric materials. Piezoelectr. Acousto Opt. 2011, 33, 612-622.

35. Kim, H.S.; Kim, J.H.; Kim, J. A review of piezoelectric energy harvesting based on vibration. Int. J. Precis. Eng. Manuf. 2001, 12, 1129-1141. [CrossRef]

36. Sodano, H.A.; Inman, D.J. A review of power harvesting from vibration using piezoelectric materials. Shock Vib. Dig. 2004, 36, 197-205. [CrossRef]

37. Granstrom, J.; Feenstra, J.; Sodano, H.A.; Farinholt, K. Energy harvesting from a backpack instrumented with piezoelectric shoulder straps. Smart Mater. Struct. 2007, 16, 1810-1820. [CrossRef]

38. Pillatsch, P.; Yeatman, E.M.; Holmes, A.S. Real world testing of a piezoelectric rotational energy harvester for human motion. J. Phys. Conf. Series 2013, 476, 012010. [CrossRef]

39. Halloran, A.; Malley, F.; McHugh, P. A review on dielectric elastomer actuators, technology, applications, and challenges. J. Appl. Phys. 2008, 104, 071101. [CrossRef]

40. Pelrine, R.; Kornbluh, R.D.; Eckerle, J. Dielectric elastomers: Generator mode fundamentals and applications. In Smart Structures and Materials 2001: Electroactive Polymer Actuators and Devices. Int. Soc. Opt. Photonics 2001, 4239, 148-156.

41. Nam, J.D.; Choi, H.R.; Koo, J.C.; Lee, Y.K.; Kim, K.J. Dielectric elastomers for artificial muscles. In Electroactive Polymers for Robotic Applications; Springer: London, UK, 2007; pp. 37-48.

42. Shankar, R.; Ghosh, T.K.; Spontak, R.J. Dielectric elastomers as next-generation polymeric actuators. Soft Matter. 2007, 3, 1116-1129. [CrossRef]

43. Prahlad, H.; Kornbluh, R.; Pelrine, R. Polymer power: Dielectric elastomers and their applications in distributed actuation and power generation. In Proceedings of the ISSS 2005 International Conference on Smart Materials Structures and Systems, Bangalore, India, 28-30 July 2005.

44. Kornbluh, D.; Pelrine, R.; Pei, Q. Electroelastomers: Applications of dielectric elastomer transducers for actuation, generation, and smart structures. In Smart Structures and Materials 2002: Industrial and Commercial Applications of Smart Structures Technologies; Society of Photo Optical: San Diego, CA, USA, 2002; Volume 4698.

45. Pelrine, R.E.; Kornbluh, R.D.; Joseph, J.P. Electrostriction of polymer dielectrics with compliant electrodes as a means of actuation. Sens. Actuators A Phys. 1998, 64, 77-85. [CrossRef]

46. Deng, Z.; Dapino, M.J. Review of magnetostrictive vibration energy harvesters. Smart Mater. Struct. 2017, 26, 103001. [CrossRef]

47. Saren, A.; Musiienko, D.; Smith, A.R.; Tellinen, J.; Ullakko, K. Modeling and design of a vibration energy harvester using the magnetic shape memory effect. Smart Mater. Struct. 2015, 24, 095002. [CrossRef]

48. Amin, M.; Farsangi, A.; Cottone, F.; Sayyaadi, H. Energy harvesting from structural vibrations of magnetic shape memory alloys. Appl. Phys. Lett. 2017, 110, 103905. 
49. Berdy, D.F.; Valentino, D.J.; Peroulis, D. Kinetic energy harvesting from human walking and running using a magnetic levitation energy harvester. Sens. Actuators A Phys. 2015, 222, 262-271. [CrossRef]

50. Wang, L.; Yuan, F.G. Vibration energy harvesting by magnetostrictive material. Smart Mater. Struct. 2008, 17, 045009. [CrossRef]

51. Poulin, G.; Sarraute, E.; Costa, F. Generation of electrical energy for portable devices: Comparative study of an electromagnetic and a piezoelectric system. Sens. Actuators A Phys. 2004, 116, 461-471. [CrossRef]

52. Arroyo, E.; Badel, A.; Formosa, F. Comparison of electromagnetic and piezoelectric vibration energy harvesters: Model and experiments, Sens. Actuators A Phys. 2012, 183, 148-156. [CrossRef]

53. Wang, X.; Liang, X.; Hao, Z. Comparison of electromagnetic and piezoelectric vibration energy harvesters with different interface circuits. Mech. Syst. Signal Proces. 2016, 72, 906-924. [CrossRef]

54. Pokale, R.S.; Deshmukh, T.R. Design and analysis of a mechanical device to harvest energy from human footstep motion. Int. J. Innov. Emerg. Res. Eng. 2016, 3, 545-550.

55. Paradiso, J.A.; Starner, T. Energy scavenging for mobile and wireless electronics. IEEE Pervasive Comput. 2005, 4, 18-27. [CrossRef]

56. Saha, C.R.; O'Donnell, T.; Wang, N.; McCloskey, P. Electromagnetic generator for harvesting energy from human motion. Sens. Actuators A Phys. 2008, 147, 248-253. [CrossRef]

57. Rome, L.C.; Flynn, L.; Goldman, E.M.; Yoo, T.D. Generating electricity while walking with loads. Science 2005, 309, 1725-1728. [CrossRef]

58. Kluger, J.M.; Sapsis, T.P.; Slocum, A.H. Robust energy harvesting from walking vibrations by means of nonlinear cantilever beams. J. Sound Vib. 2015, 341, 174-194. [CrossRef]

59. Miah, A.H.; Hyunok, C.; Md, S.; Jae, Y.P. A miniaturized electromagnetic vibration energy harvester using flux-guided magnet stacks for human-body-induced motion. Sens. Actuators A Phys. 2016, 249, $23-31$.

60. Chapius, A.; Jaquet, E. The History of the Self-Winding Watch 1770-1931; Roto-Sadag: Geneva, Switzerland, 1956.

61. Hayakawa, M. Electric Wristwatch with Generator. U.S. Patent 5,001,685, 19 March 1991.

62. Mitcheson, P.D.; Yeatman, E.M.; Rao, G.K. Energy harvesting from human and machine motion for wireless electronic devices. Proc. IEEE 2008, 96, 1457-1486. [CrossRef]

63. Huang, H.; Merrett, G.V.; White, N.M. Design of a linearized magnetic spring for body-worn inertial energy harvesters. In Proceedings of the 2012 Ninth International Conference on Networked Sensing, Antwerp, Belgium, 11-14 June 2012.

64. Fan, K.; Yu, B.; Tang, L. Scavenging energy from human limb motions. In Proceedings of the SPIE 10164, Active and Passive Smart Structures and Integrated Systems, Portland, OR, USA, 11 April 2017.

65. Donelan, J.M.; Li, Q.; Naing, V. Biomechanical energy harvesting: Generating electricity during walking with minimal user effort. Science 2008, 319, 807-810. [CrossRef]

66. Li, Q.; Naing, V.; Donelan, J.M. Development of a biomechanical energy harvester. J. Neuroeng. Rehabil. 2009, 6, 22. [CrossRef]

67. Kuang, Y.; Ruan, T.; Chew, Z.J.; Zhu, M. Energy harvesting during human walking to power a wireless sensor node. Sens. Actuators A Phys. 2017, 254, 69-77. [CrossRef]

68. Shan, Q.; Zhang, M.; Chen, Q. Inertia energy harvest of human walking to power mobile electronic. J. Electron. Meas. Instru. 2009, 23, 70-75.

69. Li, Q.; Naing, V.; Hoffer, J.A.; Weber, D.J.; Kuo, A.D.; Donelan, J.M. Biomechanical energy harvesting: Apparatus and method. In Proceedings of the 2008 IEEE International Conference on Robotics and Automation, Pasadens, CA, USA, 19-23 May 2008.

70. El-Hami, M.; Glynne, P.; White, N.M.; Hill, M. Design and fabrication of a new vibration-based electromechanical power generator. Sens. Actuators A Phys. 2001, 92, 335-342. [CrossRef]

71. Wei, X.; Liu, J. Power sources and electrical recharging strategies for implantable medical devices. Front. Energy Power Eng. China 2008, 2, 1-13. [CrossRef]

72. Dai, D.; Liu, J.; Zhou, Y. Harvesting biomechanical energy in the walking by shoe based on liquid metal magnetohydrodynamics. Front. Energy 2012, 6, 112-121. [CrossRef]

73. Dai, D.; Zhou, Y.; Liu, J. Liquid metal based thermoelectric generation system for waste heat recovery. Renew. Energy 2011, 36, 3530. [CrossRef]

74. Jia, D.; Liu, J.; Zhou, Y. Harvesting human kinematical energy based on liquid metal magnetohydrodynamics. Phys. Lett. A 2009, 373, 1305. [CrossRef] 
75. Krupenkin, T.; Taylor, J.A. Reverse electrowetting as a new approach to high-power energy harvesting. Nat. Commun. 2011, 2, 448. [CrossRef] [PubMed]

76. Mugele, F.; Duits, M.; Van, D.E. Electrowetting: A versatile tool for drop manipulation, generation, and characterization. Adv. Colloid Interface Sci. 2010, 161, 115-123. [CrossRef] [PubMed]

77. Wang, Z.L. Towards self-powered nanosystems: From nanogenerators to nanopiezotronics. Adv. Funct. Mater. 2010, 18, 3553-3567. [CrossRef]

78. Hou, T.; Yang, Y.; Zhang, H.; Chen, J. Triboelectric nanogenerator built inside shoe insole for harvesting walking energy. Nano Energy 2013, 2, 856-862. [CrossRef]

79. Fan, F.; Tian, Z.; Wang, Z. Flexible triboelectric generator. Nano Energy 2012, 1, 328-334. [CrossRef]

80. Huang, T.; Wang, C.; Yu, H. Human walking-driven wearable all-fiber triboelectric nanogenerator containing electrospun polyvinylidene fluo-ride piezoelectric nanofibers. Nano Energy 2015, 14, 226-235. [CrossRef]

81. Zheng, Y.; Cheng, L.; Yuan, M. An electrospun nanowire-based triboelectric nanogenerator and its application in a fully self-powered UV detector. Nanoscale 2014, 6, 7842-7846. [CrossRef]

82. Yang, Y.; Zhang, H.; Lin, Z. Human skin based triboelectric nanogenerators for harvesting biomechanical energy and as self-powered active tactile sensor system. ACS Nano 2013, 7, 9213-9222. [CrossRef] [PubMed]

83. Wang, S.; Xie, Y.; Niu, S. Freestanding triboelectric-layer-based nanogenerators for harvesting energy from a moving object or human motion in contact and non-contact modes. Adv. Mater. 2014, 26, 2818-2824. [CrossRef] [PubMed]

84. Xie, Y.; Wang, S.; Niu, S. Grating-structured freestanding triboelectric-layer nanogenerator for harvesting mechanical energy at 85\% total conversion efficiency. Adv. Mater. 2014, 26, 6599-6607. [CrossRef] [PubMed]

85. Mitcheson, P.D.; Sterken, T.; He, C.; Kiziroglou, M. Electrostatic microgenerators. Meas. Control 2008, 41, 114-119. [CrossRef]

86. Baginsky, I.L.; Kostsov, E.G.; Kamishlov, V.F. Two-capacitor electrostatic microgenerators. Engineering 2013, 5, 9-18. [CrossRef]

87. San, H.; Cheng, Z.; Deng, Z. Design and simulation of MEMS based radioisotope converter with electrostatic capacitive energy conversion mechanism. In Proceedings of the 2011 6th IEEE International Conference on Nano/Micro Engineered and Molecular Systems, Kaohsiung, Taiwan, 20-23 February 2011.

88. Roundy, S.; Wright, P.K.; Pister, K.S. Micro-electrostatic vibration-to-electricity converters. Fuel Cells 2002, 220, 1-10.

89. Basset, P.; Galayko, D.; Cottone, F. Electrostatic vibration energy harvester with combined effect of electrical nonlinearities and mechanical impact. J. Micromech. Microeng. 2014, 24, 035001. [CrossRef]

90. Dragunov, V.; Dorzhiev, V. Electrostatic vibration energy harvester with increased charging current. J. Phys. Conf. Ser. 2013, 476, 012115. [CrossRef]

91. Divya, K.C.; Østergaard, J. Battery energy storage technology for power systems-An overview. Electr. Power Syst. Res. 2009, 79, 511-520. [CrossRef]

92. Aneke, M.; Wang, M. Energy storage technologies and real life applications-A state of the art review. Appl. Energy 2016, 179, 350-377. [CrossRef]

93. Hadjipaschalis, I.; Poullikkas, A.; Efthimiou, V. Overview of current and future energy storage technologies for electric power applications. Renew. Sustain. Energy Rev. 2009, 13, 1513-1522. [CrossRef]

94. Dunn, B.; Kamath, H.; Tarascon, J. Electrical energy storage for the grid: A battery of choices. Science 2011, 334, 928. [CrossRef] [PubMed]

95. Liu, C.; Li, F.; Ma, L.P.; Cheng, H.M. Advanced materials for energy storage. Adv. Mater. 2010, 22 , E28-E62. [CrossRef] [PubMed]

96. Sodano, H.A.; Inman, D.J.; Park, G. Generation and storage of electricity from power harvesting devices. J. Intell. Mater. Syst. Struct. 2005, 16, 67-75. [CrossRef]

97. Wei, S.; Hu, H.; He, S. Modeling and experimental investigation of an impact-driven piezoelectric energy harvester from human motion. Smart Mater. Struct. 2013, 22, 105020. [CrossRef]

98. Sheng, W.; Zhang, T.; Xu, L. A review of power scavenging from vibration sources based on the piezoelectric effect. Mech. Sci. Tech. Aerosp. Eng. 2010, 29, 1515-1521.

99. Zanchi, V.; Papi, V.; Cecic, M. Quantitative human gait analysis. Simul. Pract. Theory 2000, 8, 127-139. [CrossRef]

100. Borowy, B.S.; Salameh, Z.M. Dynamic response of a stand-alone wind energy conversion system with battery energy storage to a wind gust. IEEE Trans. Energy Convers. 1997, 12, 73-78. [CrossRef] 
101. Fathima, A.H.; Palanisamy, K. Battery energy storage applications in wind integrated systems-A review. In Proceedings of the 2014 International Conference on Smart Electric Grid (ISEG), Guntur, India, 19-20 September 2014.

102. Chan, C.K.; Peng, H.; Liu, G.; McIlwrath, K. High-performance lithium battery anodes using silicon nanowires. Nat. Nanotech. 2008, 3, 31-35. [CrossRef]

103. Guan, M.; Liao, W.H. On the energy storage devices in piezoelectric energy harvesting. In Proceedings of the Smart Structures and Materials 2006: Damping and Isolation. Int. Soc. Opt. Photonics 2006, 6169, 61690C.

104. Ouyang, X.; Ding, S.; Fan, B.; Li, P. Development of a novel compact hydraulic power unit for the exoskeleton robot. Mechatronics 2016, 38, 68-75. [CrossRef]

105. Gonz'alez, J.L.; Rubio, A.; Moll, F. Human powered piezoelectric batteries to supply power to wearable electronic devices. Int. J. Soc. Mater. Eng. Resour. 2002, 10, 34-40. [CrossRef]

106. Indrajit, S.; Sagar, M.; Kalyan, B. A review of energy harvesting technology and its potential applications. Environ. Earth Sci. Res. J. 2017, 4, 33-38.

107. Jia, Y.; Wei, X.; Pu, J.; Xie, P.; Wen, T.; Wang, C.; Lian, P.; Xue, S.; Shi, Y. A numerical feasibility study of kinetic energy harvesting from lower limb prosthetics. Energies 2019, 12, 3824. [CrossRef]

108. Han, J.; Von, J.A.; Le, T. Novel power conditioning circuits for piezoelectric micro-power generators. In Proceedings of the Nineteenth Annual IEEE Applied Power Electronics Conference and Exposition, Anaheim, CA, USA, 22-26 February 2004; pp. 1541-1546.

109. Ottman, G.K.; Hofmann, H.F. Adaptive piezoelectric energy harvesting circuit for wireless remote power supply. In Proceedings of the 19th AIAA Applied Aerodynamics Conference, Anaheim, CA, USA, 11-14 June 2001.

110. Bonisoli, E.; Repetto, M.; Manca, N.; Gasparini, A. Electro-mechanical and electronic integrated harvester for shoes application. IEEE/ASME Trans. Mech. 2017, 22, 1921-1932. [CrossRef]

111. Rome, L.C.; Flynn, L.; Yoo, T.D. Rubber bands reduce the cost of carrying loads. Nature 2006, 444, $1023-1024$. [CrossRef]

112. Collins, S.H.; Wiggin, M.B.; Sawicki, G.S. Reducing the energy cost of human walking using an unpowered exoskeleton. Nature 2015, 522, 212-215. [CrossRef]

113. Collins, S.H.; Kuo, A.D. Recycling energy to restore impaired ankle function during human walking. PLoS ONE 2010, 5, e9307. [CrossRef]

114. Bansal, P.; Marshall, N. Feasibility of hydraulic power recovery from waste energy in bio-gas scrubbing processes. Appl. Energy 2010, 87, 1048-1053. [CrossRef]

115. Hirai, H.; Ozawa, R.; Goto, S.; Fujigaya, H. Development of an ankle-foot orthosis with a pneumatic passive element. In Proceedings of the ROMAN 2006-The 15th IEEE International Symposium on Robot and Human Interactive Communication, Hatfield, UK, 6-8 September 2006.

116. Yang, H.; Pan, M. Engineering research in fluid power: A review. J. Zhejiang Univ. Sci. A 2015, 16, 427-442. [CrossRef]

117. Chin, R.; Hsiao-Wecksler, E.T.; Loth, E. A pneumatic power harvesting ankle-foot orthosis to prevent foot-drop. J. Neuroeng. Rehabil. 2009, 6, 19. [CrossRef] [PubMed]

118. Takaiwa, M.; Noritsugu, T. Development of pneumatic walking support shoes using wearer's potential energy. In Proceedings of the JFPS International Symposium on Fluid Power, Toyama, Japan, 15-18 September 2008.

119. Zoss, A.; Kazerooni, H. Design of an electrically actuated lower extremity exoskeleton. Adv. Robo. 2006, 20, 967-988. [CrossRef]

120. Lee, S.; Oh, L.; Lee, Y.; Choi, L. Development of micro hydraulic actuator for force assistive wearable robot. In Proceedings of the IEEE ISR 2013, 24-26 October 2013; pp. 1-6.

121. Kang, T.; Kaminaga, H.; Nakamura, Y. A robot hand driven by hydraulic cluster actuators. In Proceedings of the 2014 IEEE-RAS International Conference on Humanoid Robots, Madrid, Spain, 18-20 November 2014; pp. 39-44.

122. Zhu, Y.; Zou, J.; Yang, H. Wear performance of metal parts fabricated by selective laser melting: A literature review. J. Zhejiang Univ. Sci. A 2018, 19, 95-110. [CrossRef]

123. Semini, C.; Goldsmith, J.; Manfredi, D.; Calignano, F. Additive manufacturing for agile legged robots with hydraulic actuation. In Proceedings of the 2015 International Conference on Advanced Robotics (ICAR), Istanbul, Turkey, 27-31 July 2015. 
124. Liu, Y.; Xu, L.; Zuo, L. Design, modeling, lab and field tests of a mechanical-motion-rectifier-based energy harvester using a ball-screw mechanism. IEEE/ASME Trans. Mech. 2017, 22, 1933-1943. [CrossRef]

125. Lodewyks, J.; Zurbrügg, P. Decentralized energy-saving hydraulic concepts for mobile working machines. In Proceedings of the 10th International Fluid Power Conference, Dresden, Germany, 8-10 March 2016.

126. Stelson, K.A. Saving the world's energy with fluid power. In Proceedings of the 8th JFPS International Symposium on Fluid Power, Okinawa, Japan, 25-28 October 2011.

127. Schroter, J.; Jacobs, G. Development of high speed electric drives for mobile machinery-challenges and potential solutions. In Proceedings of the 9th International Fluid Power Conference, Aachen, Germany, 24-26 March 2014.

128. Ulbricht, A.; Gude, M.; Barfuß, D.; Birke, M. Potential and application fields of lightweight hydraulic components in multi-material design. In Proceedings of the 10th International Fluid Power Conference, Dresden, Germnay, 8-10 March 2016.

129. Foglyano, K.M.; Kobetic, R.; To, C.S. Feasibility of a hydraulic power assist system for use in hybrid neuroprostheses. Appl. Bionics Biomech. 2005, 2005, 205104. [CrossRef]

130. Lee, H.; Kim, W.; Han, J.; Han, C. The technical trend of the exoskeleton robot system for human power assistance. Int. J. Precis. Eng. Manuf. 2012, 13, 1491-1497. [CrossRef]

131. Yu, T.; Plummer, A.; Iravani, P. The design, analysis and testing of a compact electrohydrostatic powered ankle prosthesis. In Proceedings of the BATH/ASME 2016 Symposium on Fluid Power and Motion Control, Bath, UK, -9 September 2016.

132. Zhang, X.; Guo, Q.; Zhao, C.; Zhang, Y.; Luo, X. Development of a lower extremity exoskeleton suit actuated by hydraulic. In Proceedings of the 2012 IEEE International Conference on Mechatronics and Automation, Chengdu, China, 5-8 August 2012; pp. 587-591.

133. Wang, Z.; Shi, H.; Wang, H.; Mei, X. An energy harvesting mechanism transfer human walking energy to hydraulic power. In Proceedings of the 2017 24th International Conference on Mechatronics and Machine Vision in Practice, Auckland, New Zealand, 21-23 November 2017.

134. Nilsson, J.; Thorstensson, A. Ground reaction forces at different speeds of human walking and running. Acta Physiol. Scand. 1989, 136, 217-227. [CrossRef]

135. Zakria, M.; Maqbool, H.F.; Hussain, T. Heuristic based gait event detection for human lower limb movement. In Proceedings of the 2017 IEEE EMBS International Conference on Biomedical \& Health Informatics (BHI), Orlando, FL, USA, 16-19 February 2017.

136. Walter, P.; Regina, K. Gait disorders in adults and the elderly: A clinical guide. Wien. Klin. Wochenschr. 2016, 129, 1-15.

137. Giakas, G.; Vasilios, B. Time and frequency domain analysis of ground reaction forces during walking: An investigation of variability and symmetry. Gait Posture 1997, 5, 189-197. [CrossRef]

138. Keller, T.S.; Weisberger, A.M.; Ray, J.L. Relationship between vertical ground reaction force and speed during walking, slow jogging, and running. Clin. Biomech. 1996, 11, 253-259. [CrossRef]

139. Sue, C.; Tsai, N. Human powered MEMS-based energy harvest devices. Appl. Energy 2012, 93, $390-403$. [CrossRef]

140. Paradiso, J.A. System for human-powered mobile computing. In Proceedings of the $200643 \mathrm{rd}$ ACM/IEEE Design Automation Conference, San Francisco, CA, USA, 24-28 July 2006; Volume 30, pp. 645-650.

141. McAdams, E.; Krupaviciute, A.; Gehin, C.; Grenier, E.; Massot, B. Wearable sensor systems: The challenges. In Proceedings of the 2011 Annual International Conference of the IEEE Engineering in Medicine and Biology Society, Boston, MA, USA, 30 Auguest-3 September 2011.

(C) 2019 by the authors. Licensee MDPI, Basel, Switzerland. This article is an open access article distributed under the terms and conditions of the Creative Commons Attribution (CC BY) license (http://creativecommons.org/licenses/by/4.0/). 